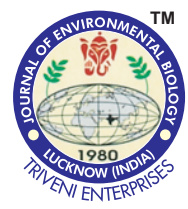

\title{
Post-embryonic development in Archaeomysis vulgaris (Nakazawa, 1910) reared in laboratory: Growth and sexual differentiation
}

\section{Authors Info \\ H.S. $\operatorname{Han}^{1}$, C.W. $\mathrm{Ma}^{2 *}$ and Y.W. Bok $^{3}$ \\ ${ }^{1}$ Korea Environment Corpoaration, 42 Hwanggyeong-ro, Incheon, South Korea \\ ${ }^{2}$ Department of Life Science and Biotechnology, Soonchunhyang University, Asan, 31538, \\ South Korea \\ ${ }^{3}$ Korea Enviromental Technology, Ansan, South Korea}

*Corresponding Author Email : cwooma@sch.ac.kr

\section{Edited by}

Dr. Sumati Gaumat

\section{Reviewed by Dr. Jong Chun Kim Dr. Dae Sun Son Dr. Ki Won Lee}

\begin{abstract}
Aim: This study will help to understand the changes in survival rate and growth of juvenile $A$. vulgaris due to changing oceanic temperature. This study proved that water temperature among environmental factors affects $A$. vulgaris's developing period of secondary sexual characters, molting frequency, daily growth, and growth ratio of post-embryonic, especially in higher water temperature.
\end{abstract}

Methodology: Archaeomysis vulgaris in South Korea were reared and analyzed under controlled condition of at $10,18,25^{\circ} \mathrm{C}$, (33-34 psu; $\left.12 / 12 \mathrm{~L} / \mathrm{D}\right)$ from hatching through a series of instars. Each specimen was individually maintained during the intermolt period, percentage increment and growth rate based on laboratory rearing.

Results: This experiment result indicated the position of sexual molt variation related to water temperature followed by the statement of these species sexual characters appeared at $4^{\text {th }}$ juvenile stage at $10^{\circ} \mathrm{C}, 6^{\text {th }}$ juvenile stage at $18^{\circ} \mathrm{C}$ and $7^{\text {th }}$ juvenile stage at $25^{\circ} \mathrm{C}$. Survival rates increased with temperature during the first juvenile stage to last molting stage. The growth rate of $A$. vulgaris at $10^{\circ} \mathrm{C}, 18^{\circ} \mathrm{C}$ and $25^{\circ} \mathrm{C}$ was $0.05,0.09$ and $0.17 \mathrm{~mm} /$ daily. Intermolt period and the growth rate of mean carapace length were inversely correlated with temperature. The growth of carapace length between abdomen to telson to the other body parts of the $A$. vulgaris were significantly relative at $10^{\circ} \mathrm{C}, 18^{\circ} \mathrm{C}$ and $25^{\circ} \mathrm{C}$. In the $6^{\text {th }}$ period.

Interpretation: This research will help to understand the relationship between the changes in survival rate, the growth of juvenile $A$. vulgaris to changing oceanic temperature. The following research will present a strategy to maintain the population of $A$. vulgaris by using shorter cycle, where it participates in reproduction at lower temperature or delay the growth for increasing survival ratio.

Key words: Archaeomysis vulgaris, Epibenthic, Mysidacea, Sexual characters, Survival ratio

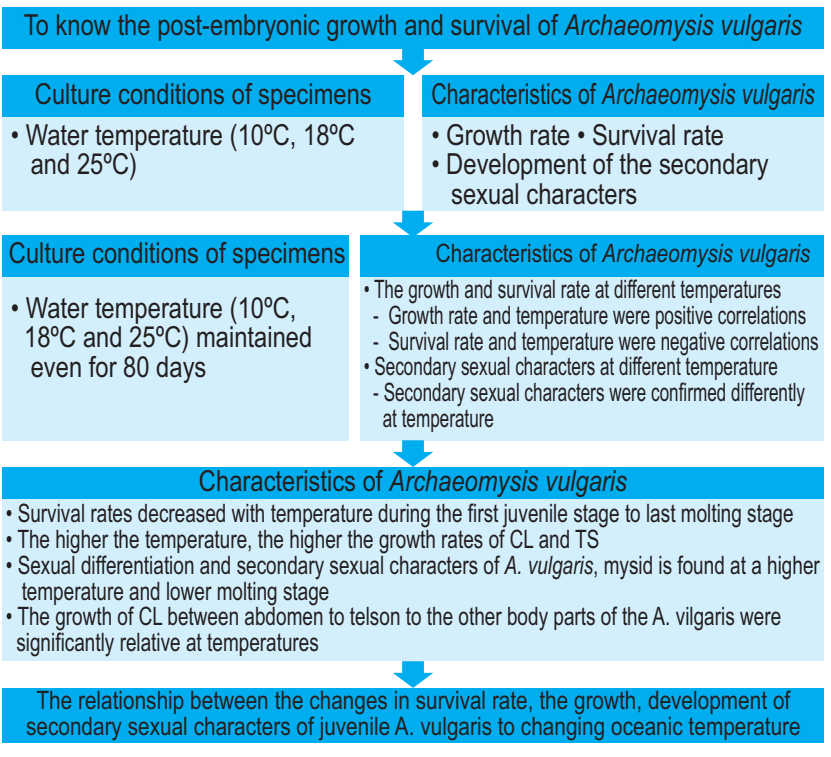

How to cite : Han, H.S., C.W. Ma and Y.W. Bok: Post-embryonic development in Archaeomysis vulgaris (Nakazawa, 1910) reared in laboratory: Growth and sexual differentiation. J. Environ. Biol., 40, 917-923 (2019). DOI: http://doi.org/10.22438/jeb/40/5(SI)/SI-12 


\section{Introduction}

Mysidae, a macro-plankton, is usually found in the shallow ocean of surf-zone and an intertidal area which exhibits an epibenthic life. As a principle feed for large crustacea, Mysidae occupies an important position within food web in the coastal ecosystem (Brown and Talbot, 1972; Lasiak, 1983; Rossouw, 1983). Post-embryonic growth and development of Mysidae are essential for ecological and biological study. In particular, the reproductive cycle and post-embryonic growth are important to understand the lifespan and population structure (Ma et al., 2001; Hong and Oh, 1989). The post-embryonic growth of Mysidae is examined to understand their reproductive characters and generations cycle in laboratory or field-collection (Mauchline, 1980). In a study on the post-embryonic growth of epibenthic mysid, Sudo (2003) reposted the embryonic growth of Acanthomysis robusta related to temperature changes and Yamada et al. (1995) investigated the survival and growth depending on feed control of Acathomysis mitsukurii. Theories on the embryonic growth of Archaeomysis sp. which are connected to same genus target species in this study, such as Hanamura's (1997) morphological study that carapace length by phases of embryonic growth, the study on taxonomical characters by phases of embryonic growth of $A$. kokuboi and $A$. japonica, by Takahashi and Kawaguchi (1996) and Jawed's (1973) study which differences in growths with environmental factors of $A$. grednitzkii and Neomysis awatschensis. Although most of the studies have been analyzed by relying on mass rearing in laboratory and field collection or embryonic growth and life cycle by individual rearing (Mauchline, 1980). There was study of sexual differentiation, survival, absolute and relative growth by using exuviae of post-embryonic growth of $A$. kokuboi in South Korea (Ma et al., 2001). A. vulgaris was studied for embryonic growth through field collection by Mastudaria et al. (1952) and morphological features by embryonic growths by Nonomura et al. (2005) in Japan.

This study analyzes intermolt period, survival rate of each molting stages, daily growth and relative growth through individual rearing experiment for understanding the embryonic growth of $A$. vulgaris with relative dominance among Mysidae in the west coast of Korea.

\section{Materials and Methods}

Collection and culture conditions of specimens : Ovigerous females of Archaeomysis vulgaris was collected in the surf zone of Hakampo beach, on the west coast of South Korea. They were gradually acclimatized to each experimental temperature three days. Following condition was maintained during the experiment until the juveniles hatched: regime was 6:18 L:D, they were fed ad libitum with < 24-hr old Artemia sp., nauplii and water was replaced every 2 days.
With the advancement in experiment, each ovigerous female released average 35 juveniles which were divided into three groups by same brood to expose to three temperature regimes $\left(10^{\circ} \mathrm{C}, 18^{\circ} \mathrm{C}\right.$ and $\left.25^{\circ} \mathrm{C}\right)$. The juveniles were kept individually in $100 \mathrm{ml}$ glass beakers in three different controlled temperature incubators under 12:12 L:D regime during the experiment. They were fed ad libitum with $<24$-hr old Artemia sp. nauplii and water was replaced every 2 days. All incubators were checked twicw a day to check excuvia.

Date collection : The total length ( $T L$ ), carapace length $(C L)$ and telson length (TS) were determined by measuring the exuvia for obtaining more accurate measurements by reducing stress due to handling. The measurements were recorded as digital images by image analysis software (Image-pro Plus 3.0) with a stereomicroscope (Fig. 1).

Development of secondary sexual characters in each incubators were divided into three stages: Stage I juveniles showed should no differentiation. Stage II juveniles were developed oostegites (female) and $2^{\text {nd }}$ ramus of pleopods (male). Stage III juveniles developed into marsupium (female) and

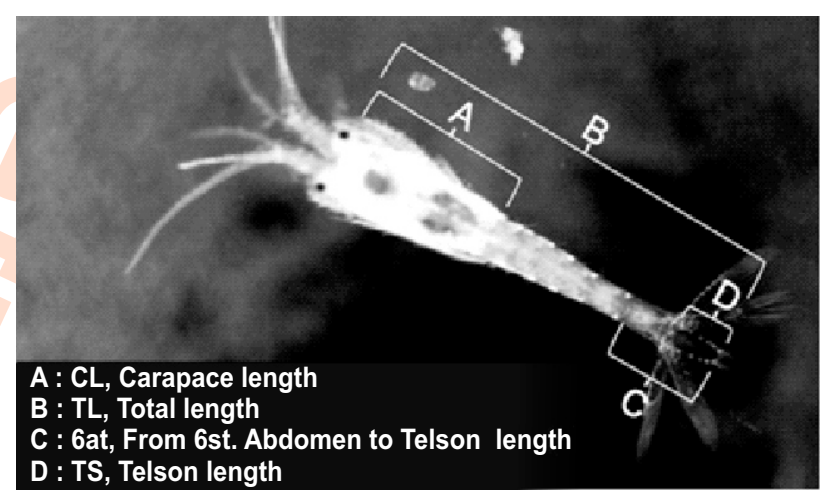

Fig. 1 : Morphometric measurements of Archaeomysis vulgaris (Nakazawa, 1910).

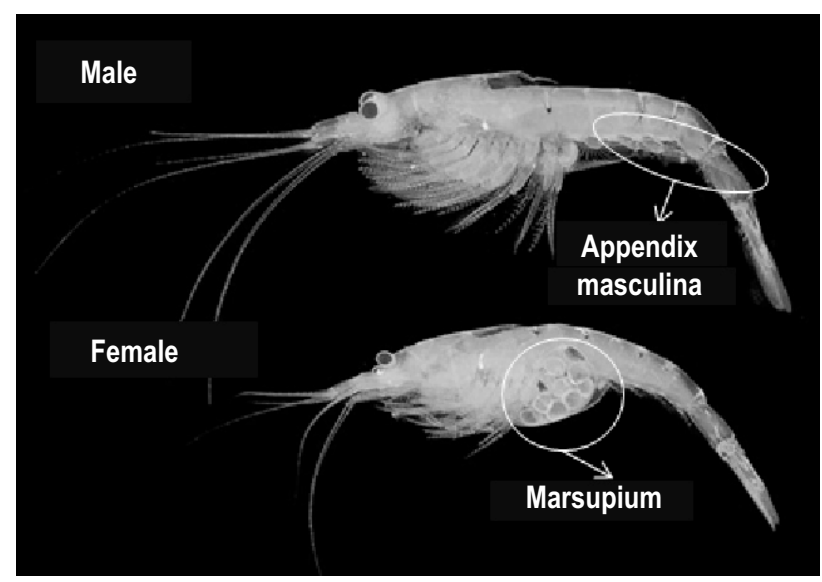

Fig. 2 : Secondary sexual characters of male and female Archaeomysis vulgaris. 
appendix masculine (male) (Fig. 2). The growth of juveniles data was collected in each incubator with growth rate of carapace length, a day after releasing each molt stages, intermolt period and sexual moult. The growth results were analyzed based on the body part-growth of post-embryonic and relative growth between carapace length. The observation was carried until all specimens in a series were dead.

Statistics analyses : All data were checked with KomogrovSmirnov for normality and homogeneity of variance. The effect of temperature was tested for significance using one-way analysis of variance. A chi-square test was used for comparing the percentage surviving of individuals until given instars and daily growth rates at three temperature regimes. A pearson correlation analysis was determined between daily growth rates and temperature of each incubator. Statistical correlation analysis of Pearson product moments was accomplished using SPSS ver. 15. All box plots were show as mean, standard error and standard deviation.

\section{Results and Discussion}

The survival duration at each temperature of rearing are as follows: 80 days at $10^{\circ} \mathrm{C}, 71$ days at $18^{\circ} \mathrm{C}$ and 45 days at $25^{\circ} \mathrm{C}$. After 40 days, the survival rate at each temperature are as follows: over $80 \%$ at $10^{\circ} \mathrm{C}$ and $18^{\circ} \mathrm{C}$ and relatively low rate of $40 \%$, at $25^{\circ} \mathrm{C}$, after which the survival rate decreased abruptly. This result is consistent with the fact that the survival duration of crustacean is inversely proportional to temperature: higher the temperature, shorter the duration (Fig. 3).

At $10^{\circ} \mathrm{C}$, over $80 \%$ of survival rate was observed until $6^{\text {th }}$ molting stage, and then survival rate decreased rapidly. At $18^{\circ} \mathrm{C}$, the survival ratio was about $80 \%$ until $5^{\text {th }}$ molting stage and decreased rapidly at the end of the term. At $25^{\circ} \mathrm{C}$, the ratio reduced to $72 \%$ until $5^{\text {th }}$ and $8^{\text {th }}$ molting stage but later decreased by $13 \%$ at each molting stage. The decrease in mode of survival ratio was same at $10^{\circ} \mathrm{C}$ and $18^{\circ} \mathrm{C}$, accept for $25^{\circ} \mathrm{C}$ (Fig. 4). Survival rate of Archaeomysis vulgaris juveniles showed best survival at $10^{\circ} \mathrm{C}$. However, more individuals reached later instars at higher temperature $\left(25^{\circ} \mathrm{C}\right)$ (Fig. 4). It has been reported that in general, the crustacean survival period is shorter when the temperature rises and longer when the temperature decreases (Rudolf and Isabelle, 1982; Minagawa, 1990; Domingues et al., 1999; McKenney, 1987). Growth studies of $A$. kokuboi by Ma et al. (2001) and Leptomys lingura and Hemimysis speluncula by Gaudy and Guerin (1979) also reported that temperature, duration of survival and growth were readjusted and the intermoult period was inversely proportional.

Both males and females exhibited secondary sexual characters after going through $6^{\text {th }}$ and $7^{\text {th }}$ molting stage at $18^{\circ} \mathrm{C}$ and $25^{\circ} \mathrm{C}$. After $8^{\text {th }}$ and $9^{\text {th }}$ molting stage at $18^{\circ} \mathrm{C}$ and $25^{\circ} \mathrm{C}$, the oostegites of females developed into marsupium, and the appendix masculine of males developed enough to mate and

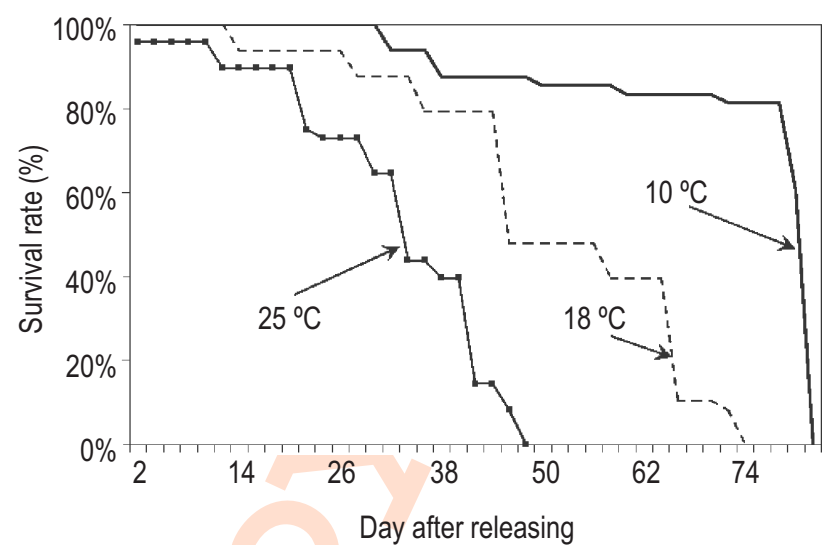

Fig. 3 : Survival rates plotted against time of post-embryonic Archaeomysis vulgaris reared at three temperatures.

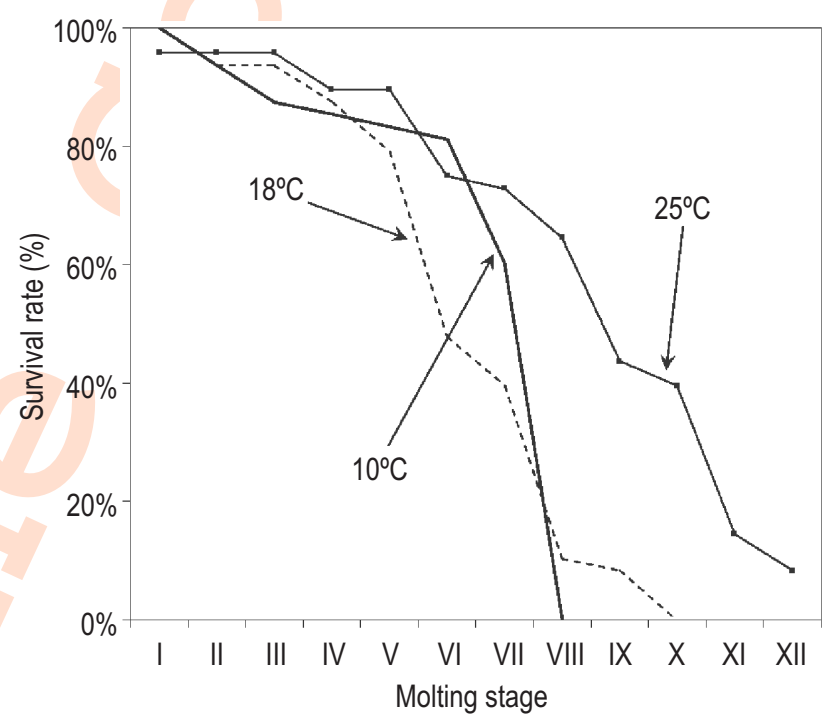

Fig. 4 : Survival rates at each molting stage of post-embryonic Archaeomysis vulgaris reared at three temperatures.

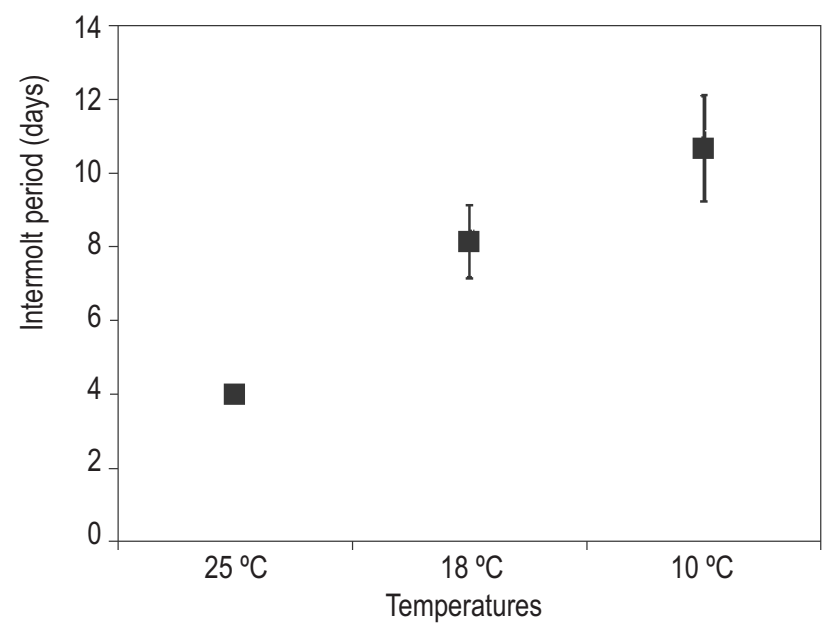

Fig. 5 : Morphometric measurements taken on Archaeomysis vulgaris (Nakazawa, 1910). 
Table 1 : Duration of each development stage, carapace length and development of secondary sexual characters of post-embryonic Archaeomysis vulgaris reared at three temperatures

\begin{tabular}{|c|c|c|c|c|c|c|c|c|}
\hline \multirow[t]{2}{*}{$\begin{array}{l}\text { Gener- } \\
\text { ations }\end{array}$} & \multirow[t]{2}{*}{$\begin{array}{l}\text { Development } \\
\text { stages }\end{array}$} & \multicolumn{3}{|c|}{ Intermolt period (days) } & \multicolumn{2}{|c|}{$\begin{array}{l}\text { Carapace length } \\
(\mathrm{mm})\end{array}$} & \multicolumn{2}{|c|}{ Development of secondary sexual characters } \\
\hline & & Instars & Total & Mean & $\begin{array}{l}\text { Standard } \\
\text { deviation }\end{array}$ & Instars & Female & Male \\
\hline \multirow[t]{7}{*}{$10^{\circ} \mathrm{C}$} & I & 15.8 & 15.8 & 0.96 & \pm 0.017 & 0.96 & no differentiation & no differentiation \\
\hline & $\|$ & 15.4 & 31.2 & 1.11 & \pm 0.018 & 0.14 & no differentiation & no differentiation \\
\hline & III & 7.5 & 38.7 & 1.26 & \pm 0.018 & 0.16 & no differentiation & no differentiation \\
\hline & IV & 10.6 & 49.3 & 1.52 & \pm 0.020 & 0.25 & oostegites & $2^{\text {nd }}$ ramus of pleopods \\
\hline & V & 9.9 & 59.2 & 1.83 & \pm 0.018 & 0.32 & oostegites & $2^{\text {nd }}$ ramus of pleopods \\
\hline & $\mathrm{VI}$ & 12.3 & 71.5 & 2.27 & \pm 0.018 & 0.44 & oostegites & $2^{\text {nd }}$ ramus of pleopods \\
\hline & VII & 8.3 & 79.8 & 2.66 & \pm 0.017 & 0.39 & oostegites & $2^{\text {nd }}$ ramus of pleopods \\
\hline \multirow[t]{9}{*}{$18^{\circ} \mathrm{C}$} & 1 & 5.8 & 5.8 & 0.95 & \pm 0.023 & 0.95 & no differentiation & no differentiation \\
\hline & $\|$ & 8.1 & 13.9 & 1.07 & \pm 0.022 & 0.13 & no differentiation & no differentiation \\
\hline & III & 8.3 & 22.2 & 1.24 & \pm 0.024 & 0.17 & no differentiation & no differentiation \\
\hline & IV & 6.0 & 28.2 & 1.52 & \pm 0.021 & 0.27 & no differentiation & no differentiation \\
\hline & V & 8.1 & 36.3 & 1.82 & \pm 0.024 & 0.30 & no differentiation & no differentiation \\
\hline & VI & 9.4 & 45.7 & 2.25 & \pm 0.021 & 0.44 & oostegites & $2^{\text {nd }}$ ramus of pleopods \\
\hline & VII & 11.6 & 57.3 & 2.64 & \pm 0.027 & 0.39 & oostegites & $2^{\text {nd }}$ ramus of pleopods \\
\hline & VIII & 8.5 & 65.8 & 3.03 & \pm 0.018 & 0.38 & marsupium & appendix masculine \\
\hline & IX & 5.2 & 71.0 & 3.48 & \pm 0.013 & 0.45 & marsupium & appendix masculine \\
\hline \multirow[t]{12}{*}{$25^{\circ} \mathrm{C}$} & I & 1.7 & 1.7 & 1.17 & \pm 0.010 & 1.17 & no differentiation & no differentiation \\
\hline & $\|$ & 3.1 & 4.8 & 1.20 & \pm 0.013 & 0.03 & no differentiation & no differentiation \\
\hline & III & 3.6 & 8.4 & 1.31 & \pm 0.013 & 0.10 & no differentiation & no differentiation \\
\hline & IV & 4.3 & 12.7 & 1.53 & \pm 0.016 & 0.22 & no differentiation & no differentiation \\
\hline & V & 4.6 & 17.3 & 1.78 & \pm 0.015 & 0.25 & no differentiation & no differentiation \\
\hline & VI & 3.7 & 21.0 & 2.01 & \pm 0.020 & 0.23 & no differentiation & no differentiation \\
\hline & VII & 4.0 & 25.0 & 2.27 & \pm 0.018 & 0.26 & oostegites & $2^{\text {nd }}$ ramus of pleopods \\
\hline & VIII & 4.6 & 29.6 & 2.49 & \pm 0.021 & 0.21 & oostegites & $2^{\text {nd }}$ ramus of pleopods \\
\hline & IX & 4.3 & 33.9 & 2.78 & \pm 0.015 & 0.29 & marsupium & appendix masculina \\
\hline & $x$ & 3.5 & 37.4 & 3.00 & \pm 0.014 & 0.22 & marsupium & appendix masculina \\
\hline & $X I$ & 3.7 & 41.1 & 3.28 & \pm 0.036 & 0.28 & marsupium & appendix masculina \\
\hline & XII & 4.4 & 45.5 & 3.55 & \pm 0.036 & 0.27 & marsupium & appendix masculina \\
\hline
\end{tabular}

reproduce. At $10^{\circ} \mathrm{C}$, individuals developed male appendix masculine and marsupium were not observed. Sexual differentiation and secondary sexual characters of $A$. vulgaris, mysid was found at a higher temperature and lower molting stage. After oostegites, $2^{\text {nd }}$ ramus of pleopods at $18^{\circ} \mathrm{C}$ and $25^{\circ} \mathrm{C}$ and then two molting stages, the marsupium and appendix masculine are maturated enough to participate in reproduction. Nakasawa (1910) reported that in $A$. vulgaris the number of pre-puberty (development secondary sexual characters) instars varied between generations, maturing at different times of the year, and it is likely that limited variation within species is fairly general. Although this study showed difference in the position of sexual moult between temperatures, the effects of temperature on the total number of pre-puberty moults could not be examined since observations at a lower temperature $\left(10^{\circ} \mathrm{C}\right)$ were not possible. However, different stages of sexual moult may influence the position of puberty instar, indicating that the position of both sexual and puberty moults can vary between individuals in relation to temperature changes in the field.
According to the result, in crustaceans, higher the temperature, shorter is the intermolt period and vice-versa, including Mysidae. Furthermore, the intermolt period was also shorter when temperature was high: $10.7 \pm 1.4$ days at $10^{\circ} \mathrm{C} ; 8.1 \pm 1.0$ days at $18^{\circ} \mathrm{C} ; 4.0 \pm 0.2$ days at $25^{\circ} \mathrm{C}$. However, there was no statistical outstanding difference between $18^{\circ} \mathrm{C}$ and $10^{\circ} \mathrm{C}$ series (Fig. 5).

The daily growth of $A$. vulgaris $C L$ and TS depending on rearing temperatures are as follows: $\mathrm{CL}: 0.07 \pm 0.01$ /day and TS: $0.05 \pm 0.01 /$ day at $10^{\circ} \mathrm{C} ; \mathrm{CL}: 0.11 \pm 0.01 /$ day and TS: $0.09 \pm 0.01$ /day at $18^{\circ} \mathrm{C}$; $\mathrm{CL}: 0.14 \pm 0.01$ /day and TS: $0.05 \pm 0.01$ /day at $25^{\circ} \mathrm{C}$, suggesting that higher the temperature, higher the growth rates of CL and TS. However, no statistical difference was found in daily growth of $\mathrm{CL}$ between $18^{\circ} \mathrm{C}$ and $10^{\circ} \mathrm{C}$ (Fig. 6).

The carapace was released from marsupium at $25^{\circ} \mathrm{C}$, after 20 days its length was about $2.8 \mathrm{~mm}$. It had a marsupium of female and appendix masculina of male. It took about 26 days to be $2.8 \mathrm{~mm}$ at $18^{\circ} \mathrm{C}, 40$ days at $10^{\circ} \mathrm{C}$. Intermoult period increased 


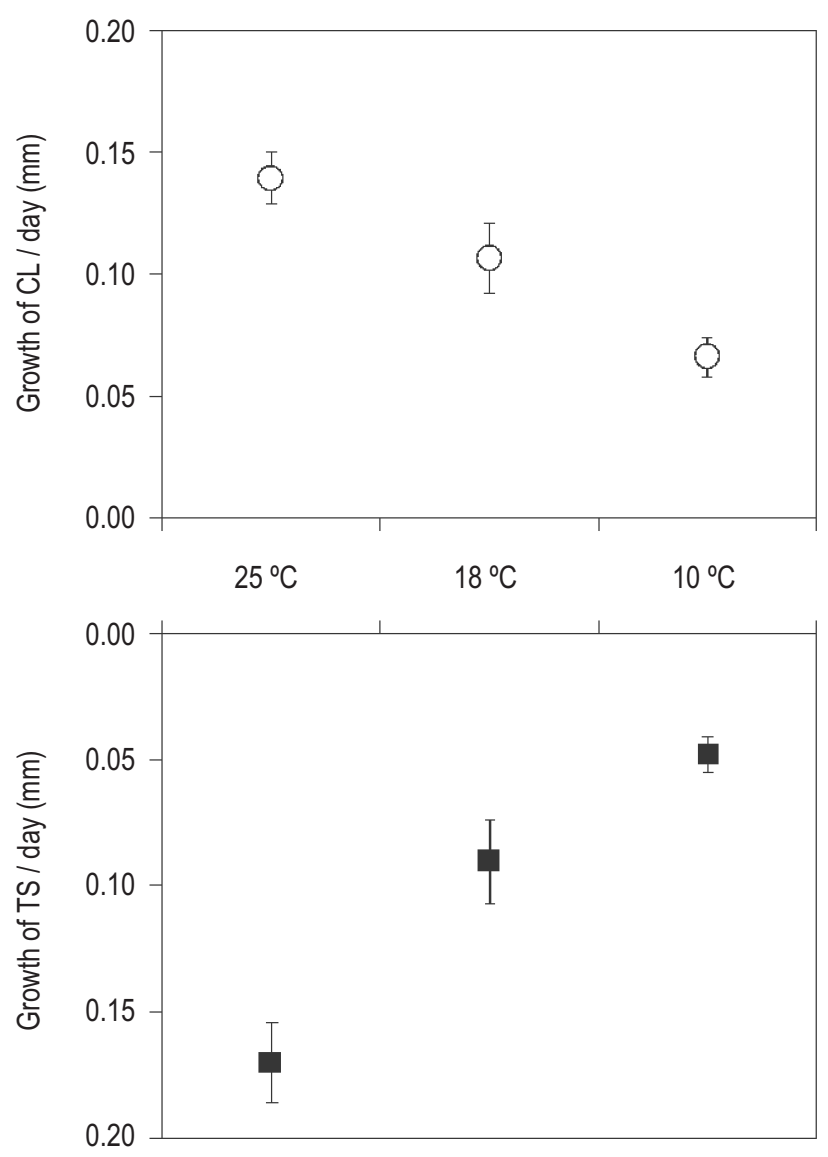

Fig. 6 : Daily growth rate of post-embryonic Archaeomysis vulgaris reared at three temperatures.

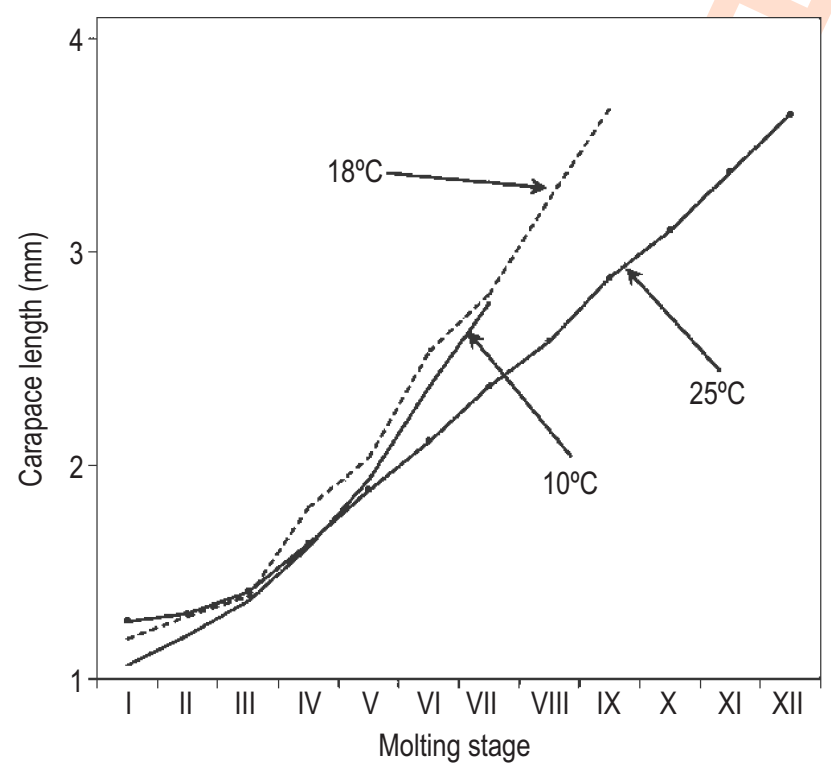

Fig. 7 : Sequence of molting stages plotted against carapace length of post-embryonic Archaeomysis vulgaris reared at three temperatures.

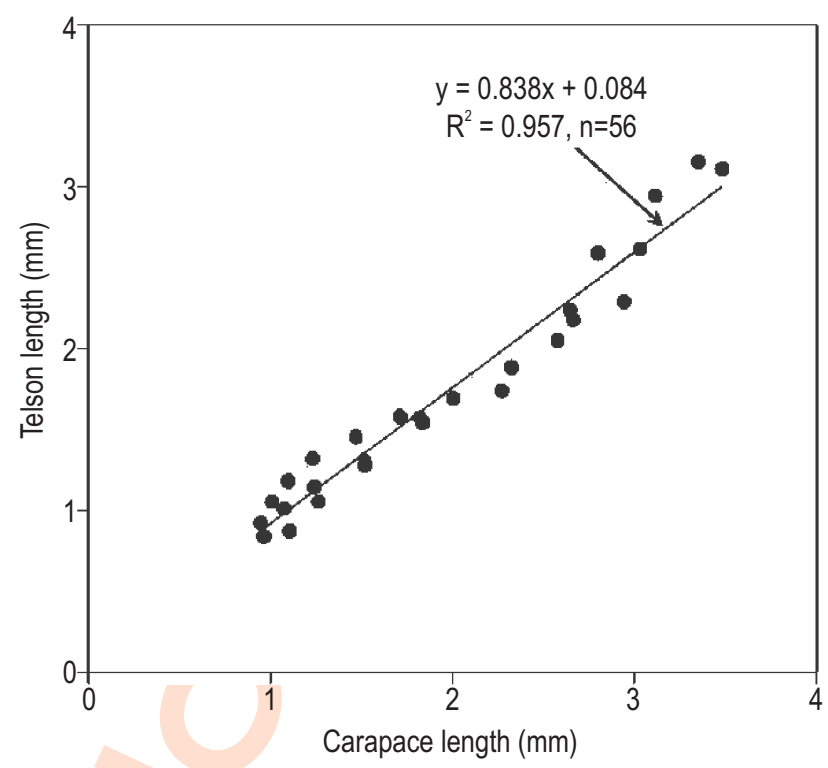

Fig. 8 : Relationship between carapace length and telson length of postembryonic Archaeomysis vulgaris.

steadily with premoult size at all temperature. This is in confirmation with the previous studies conducted on crustaceans (Mauchline, 1976, 1977; Hartnoll, 1982). As most study allows the fact of carapace length tends to be longer at a lower temperature. This lengthening research consistently reported for large number of crustacean study (Hartnoll, 1982; Mohamedeen and Hartnoll, 1989). The position of sexual moult varied at different temperature. First external sexual differentiation in females and males appeared at $4^{\text {th }}$ moult at lowest temperature, and $2^{\text {nd }}-3^{\text {th }}$ moult appeared at higher temperature than previous moult. This demonstrates that the onset of sexual differentiation can be affected by changes in ambient temperature. The full development of marsupium or appendix masculine, the puberty instar was consistent after $8^{\text {th }}$ moult at $18^{\circ} \mathrm{C}$ and $10^{\circ} \mathrm{C}$. The results revealed that the period of marsupium and appendix masculine were developed enough to take part in reproduction among $A$. vulgaris population inhabiting the west coast of Korea, followed by summer, spring generation and overwintering generation (Fig. 7).

The daily growth rate of $A$. vulgaris $C L$ and TS were higher at high temperature. As a result, it was found that among juveniles of $A$. vulgaris, inhabiting the west coast of Korea, actively recruited at high-temperature water takes a shorter time to reproduce, than any other temperature group.

$\mathrm{CL}$ and TS of 56 individuals among $A$. vulgaris were randomly measured and compared to show that the $\mathrm{CL}$ and TS ratio was $1: 0.838$, and factors were closely correlated (Pearson's correlation $\left.\mathrm{R}^{2}>0.5, \mathrm{p}<0.05\right)$. From the growth analysis using $A$. vulgaris $\mathrm{CL}$, it is reported that precise result values were not easily found due to some factors such as transformation, damage and loss of carapace. However, the growth study of $A$. kokuboi by Ma et al. (2001) and Neomysis integer by Astthorsson and Ralph 


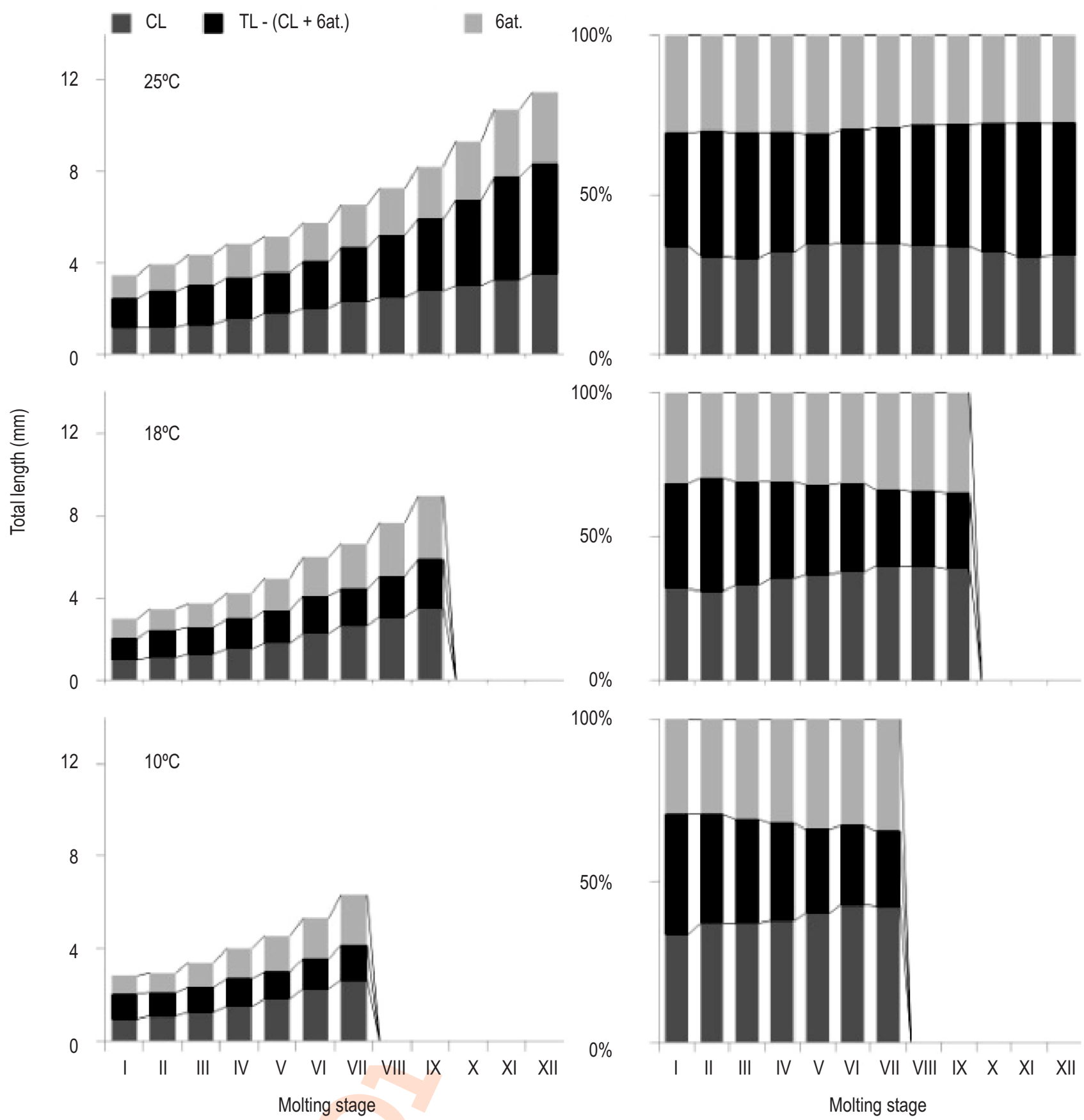

Fig. 9 : Relative growth of carapace length, 6 at. (from $6^{\text {th }}$ abdomen to telson) and other body parts of post-embryonic Archaeomysis vulgaris reared at three temperatures.

(1984) reported that it is convenient to measure TS as a measuring part for growth analysis. Thus, the study suggests that TS be used as a material for growth study of mysidae, including $A$. vulgaris (Fig. 8).

The post-embryonic growth of mysidae, including $A$. vulgaris varied according to each part at distinct temperatures. At some point, even among $A$. vulgaris population, some individuals recruited at winter and spring were determined to have $C L$ and 6 at (From 6st. abdomen to telson legth). morphologically larger than other parts. With this critical research, breeding experiments of $A$. vulgaris showed that the peeling interval remained almost equilibrium at all temperature intervals, consistent with the study of isochronal development of Miller et al. (1977)(Fig. 9). 


\section{Acknowledgment}

This work was supported in part by the Soonchunhyang University Research Fund.

\section{References}

Astthorsson, O.S. and R. Ralph: Growth and moulting of Neomysis integer (Crustacea: Mysidacea), Mar. Biol., 79, 55-61 (1984).

Brown, A.C. and M.S. Talbot: The ecology of sandy beaches of the Cape Peninsula, South Africa Part 3. A study of Gastrosaccus psammodytes Tattersall (Crustacea: Mysidacea). Trans. Roy. Soc. South Africa, 40, 309-333 (1972).

Domingues, P.M., P.E. Turk, J.P. Andrade and P.G. Lee: Culture of the mysid, Mysidopsis almyra (Bowman), (Crustacean: Mysidacea) in a static water system: Effects of density and temperature on production, survival and growth. Aquac. Res., 30, 135-143 (1999).

Gaudy, R. and J.P. Guerin: Écophysiologie comparée des mysidacés Hemimysis speluncola Ledoyer (Cavernicole) et Leptomysis lingvura G.O. Sars (non cavernicole). Action de la température sur la croissance en élevage. J. Exp. Mar. Biol. Ecol., 38, 101-119 (1979).

Hanamura, Y.: Review of taxonomy and biogeography of shallow-water mysid of the genus Archaeomysis (Crustacea: Mysidacea) in the North Pacific Ocean. J. Nat. Histol., 31, 669-711 (1997).

Hartnoll, R .G.: Growth. In: The Biology of Crustacea Vol. 2: Embryology, Morphology and Genetics (Eds.: L.G. Abele). Academic Press, pp. 111-196 (1982)

Hong, S.Y. and C.W. Oh: Ecology of sand shrimp, Crangon affinis in the Nakdong river estuary, Korea. J. Kor. Bull. Fish. Soc., 22, 351-362 (1989).

Jawed, M.: Effects of environmental factors and body size on rate of oxygen consumption in Archaeomysis grebnitzkii and Neomysis awatschensis (Crustacea: Mysidae). J. Mar. Biol., 21, 173-179 (1973).

Lasiak, T.A.: The impact of surf-zone fish communities on faunal assemblages associated with sandy beaches: A review. Sandy Beaches Ecosys., 19, 32-46 (1983).

Ma, C.W., S.Y. Hong, C.W. Oh and R.G. Hartnoll: Post-embryonic growth and survival of Archaeomysis kokuboi li, 1964 (Mysidacea) reared in the laboratory. Crustaceana, 74, 347-362 (2001).

Matsudaira, C., T. Kariya and T. Tsuda: The study of biology of a mysid Gastrosaccus vulgaris Nakasawa. Tohoku J. Agricul. Res., 3, 155174 (1952).

Mauchline, J.: Growth in shrimp, crab and lobsters. J. Cons., 37, 162-169
(1977).

Mauchline, J.: The biology of mysids and euphausiids. Adv. Mar. Biol., 18, $1-681(1980)$

Mauchline, J.: The Hiatt growth diagram for Crustacea. Mar. Biol., 35, 7984 (1976).

McKenney, C.L. Jr.: Optimization of environmental factors during the life cycle of Mysidopsis bahia. Environmental Research Brief EPA/600/M-87/004, U.S. Environmental Protection Agency, Gulf Breeze, Florida, 1-6 (1987).

Minagawa, M.: Influence of temperature on survival, feeding and development of larvae of the red frog crab, Ranina ranina (Crustacea, Decapoda, Raninidae). Bull. Japan. Soc. Sci. Fish., $56,755-760(1990)$

Miller, C.B., J.K. Johnson and D.R. Heinle: Growth rules in the marine copepod genus Acartia. Limnol. Oceanogr., 22, 326-335 (1977).

Mohamedeen, H. and R.G. Hartnoll: The effect of variation in temperature and food supply on the growth of post-larval Carcinus maenas. In: Proceedings of 21st European Marine Biology Symposium (Eds.: R.Z. Klekowski, E. Styczynska-Jurewicz and L. Falkowski). Polish Ac. Sci. Wroclaw, pp. 115-122 (1989).

Nakazawa, K.: Notes on Japanese Schizopoda. Annotationes Zoologicae Japonenses, 7, 247-261 (1910).

Nonomura, T., Y. Hayakawa, Y. Suda and J. Ohitomi: Practical identification of sand-burrowing mysid, Archaeomysis vulgaris (Crustacea: Mysidacea) and its biological characteristics. Plankton J. Bio. Ecol., 52, 48-57 (2005).

Rossouw, G. J.: The importance of non-teleost fishes (Elasmobranches) in the surf zone with special reference to Rhinobatus annulatus. Sandy Beaches Ecosys., 19, 85-98 (1983).

Rudolf, S.S. and P.W. Isabelle: Significance of temperature to larval survival and length of development in Balanus eburneus (Crustacea: Cirripedia). Mar. Ecol. Prog. Ser., 9, 43-49 (1982).

Sudo, $\mathrm{H}_{\text {: }}$ : Effect of temperature on growth, sexual maturity and reproduction of Acanthomysis robusta (Crustacea: Mysidacea) reared in the laboratory. J. Mar. Biol., 143, 1095-1107 (2003).

Takahashi, K. and K. Kawaguchi: Practical key characters to identify the closely related sand-burrowing mysids Archaeomysis kokuboiand A. japonica (Mysidacea: Gastrosaccinae) throughout all developmental stage. Bull. Plankton Soc. Japan, 43, 133-137 (1996).

Yamada, H., T. Kawamura, T. Takeuchi and Y. Yamashita: Effects of dietary condition on the survival, growth and reproduction of Acanthomysis mitsukurii (Crustadea, Mysidacea). Bul. Plankton Soc. Japan, 42, 43-52 (1995). 